\title{
Use of large irrigation pumping stations for highly manual daily regulation of capacities in the energy system of the Republic of Uzbekistan
}

\author{
Boboraim Urishev ${ }^{2^{*}}$, Muradilla Mukhammadiev ${ }^{1}$, Abdurauf Abduaziz uulu ${ }^{1}$, and Hojiakbar \\ Murodov ${ }^{1}$ \\ ${ }^{1}$ Tashkent state technical university, Tashkent, Uzbekistan \\ ${ }^{2}$ Karshi Institute of Engineering and Economics, Tashkent, Uzbekistan
}

\begin{abstract}
Information about the problems arising from the uneven production and consumption of energy in power systems, including in the power system of the Republic of Uzbekistan, is given on the example of a daily electrical load schedule. It is noted that to successfully solve these problems, energy is accumulated in the hours of minimum consumption so that it can be used in peak hours with high consumption, and for this purpose, pumped storage power plants are used. A diagram of hydraulic energy storage is given at large pumping stations used to accumulate water in the upper reservoir in hours of minimum loads, and the accumulated volume of water is directed to generate energy, which can be used by pumping stations to supply additional water to its consumers, replenishing its losses in hours of hydraulic energy storage. The method of selection and optimization of the main parameters of this complex, based on minimizing fuel consumption in power plants while limiting the amount of accumulated energy based on the capabilities of water and energy resources of pumping stations, is presented. The calculations using the example of the Syrdarya thermal power plant show that with the integration of five nearby pumping stations into the process of energy storage and generation, significant cost savings are achieved, and the daily load schedule is significantly leveled.
\end{abstract}

\section{Introduction}

As you know, one of the main issues in the energy sector is to ensure maximum compliance of the dynamics of electricity production with the process of its consumption, i.e., production capacity at any moment of time must provide consumption capacity. Therefore, when planning the production of electricity, it is necessary to consider the mode of its consumption in time, i.e., the electrical load graph. The daily irregularity of the load schedule, the presence of peaks, and sharp drops in the level of power consumption create

*Corresponding author: bob_urishev@mail.ru 
technical problems for energy producers associated with the need to implement regular changes in the capacity of power plants [1-7].

The main of these problems are the following $[8,9,10]$ :

- firstly, the efficiency of using the installed capacity of power equipment in thermal power plants (TPP) decreases, which is the most important factor affecting its payback; - secondly, the frequent operation of power equipment in a variable mode dramatically increases fuel consumption at thermal power plants and leads to premature wear of the equipment;

- thirdly, the technical possibilities of reducing and increasing the capacity of the generating equipment of TPP may be insufficient to compensate for changes in consumption; in this case, excess electrical power is transferred to other regions (or obtained from other regions), which is associated with significant energy losses.

It should be noted that the problem of uneven electricity consumption is the main problem in the electric power industry, which directly affects the efficiency and reliability of equipment operation.

This problem is also typical for the energy system of the Republic of Uzbekistan. Daily graphs of electrical load in the Republic are characterized by significant unevenness (Figure. 1)

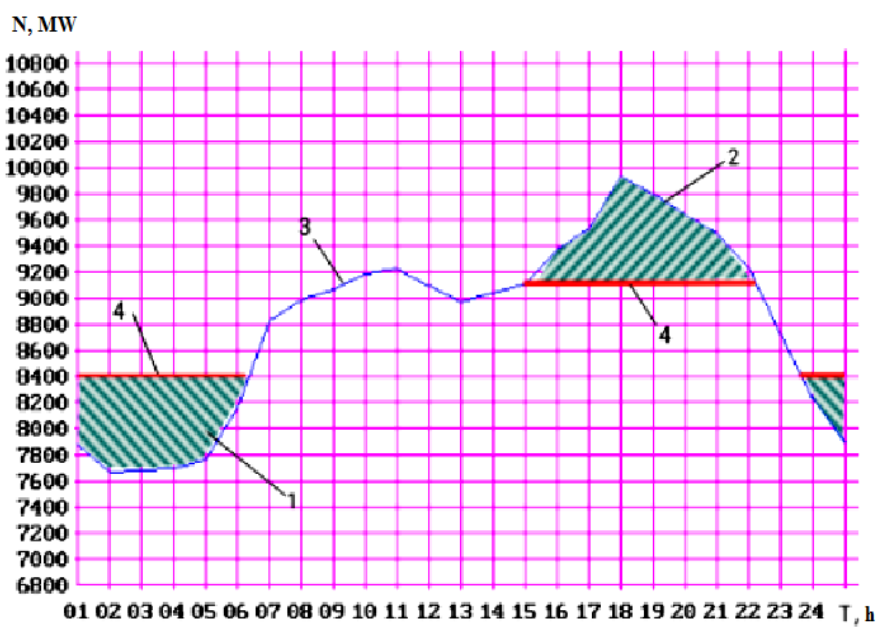

Fig. 1. Change in the daily schedule for the generation and accumulation of electricity in the energy system of the Republic of Uzbekistan dated 12/18/2019: 1 is energy consumption mode (pumping mode); 2 is power generation mode (turbine mode); 3 is daily load schedule; 4 is line of schedule change due to energy storage.

Analysis of the dynamics of changes in power consumption modes in the Republic shows that a further increase in the unevenness of the electrical load graphs should be expected in the future. This is due to an increase in the share of non-industrial small and medium-sized businesses, increasing energy consumption by the population due to an increase in their number and living standards.

In the world energy supply practice, the solution to the problem of uneven electricity consumption is achieved either by creating special maneuverable power equipment (peak power plants, gas turbine power plants) or by using batteries that consume surplus electricity during periods of the general decrease in the load in the power system and deliver it during periods of increased consumption $[5,9,10]$. In the power plants of our Republic, gas turbine power units are used to solve this problem. 
Numerous studies prove that the use of maneuverable thermal power units or power plants operating in a variable load mode leads to significant overconsumption of fuel, a decrease in the efficiency of using the installed capacity, a decrease in the service life of the equipment, and other negative consequences [4-6].

The most promising way to solve this problem is using storage systems, which are simultaneously a highly maneuverable source of peak power and a consumer regulator [911]. This is done in this way. Accumulation systems, operating in the mode of consumerregulator during the period of night load minima (from $23^{30}$ to $6^{20}$, Figure. 1) accumulate the required amount of energy, thereby preventing the shutdown of power units at TPP and at peak hours of the load schedule (from $15^{00}$ to $22^{20}$ Figure. 1), the accumulated energy is used to cover the needs of the power system in electricity (without the inclusion of additional capacity in TPP). Thus, the number of switching on and off at TPP is significantly reduced, and the coefficient of the unevenness of the load curve, which is indirectly an indicator of the reliability of the power system, significantly increases, for example, for the graph shown in Fig. 1 it increases from 0.78 to 0.92 .

Currently, in terms of technological readiness and low capital costs, pumped storage power plants (PSPP) are significantly ahead of all other energy storage systems; today, they account for $98 \%$ of the accumulated energy in the world [13-15].

The structure of the PSPP consists of hydroelectric and pumping units designed to generate electricity and pump water from the lower reservoir to the upper one, which is a storage of hydraulic energy.

Often the volumes of water in the upper and lower reservoirs at a fixed time do not match since the time of the turbine operation does not coincide with the time of the pumping regime. However, the design volumes of the reservoirs are equal.

The main disadvantages of PSPP are high capital costs associated with the construction of reservoirs of significant volumes, the need to create large heads or water flows, which is not always possible due to geographic conditions [16-18].

Taking this circumstance into account, we propose using water resources, equipment, and ready-made conditions to create a pressure available at the disposal of large pumping stations of the Republic.

\section{Methods}

Pumping stations (PS) of irrigation systems are large energy consumers, and often their work is seasonal and depends on the accepted procedure for irrigation. At present, irrigation pumping stations consume $10 \ldots 12 \%$ of electricity from the nationwide energy consumption [19].

The average indicators of the time use factors and the installed capacity of the PS are 0.27 and 0.25 , respectively, which is associated with the seasonality of their operation and the high variability of the supplied water flow.

Most of the PS operates for $4 \ldots 8$ months a year in a continuous mode with varying $Q_{P S}$ flow rates and little changing heads. In our opinion, under these conditions, it would be advisable to use the free capacities of large PS for pumped storage, adapting their operating mode to the operating modes of TPP, which are the source of power supply for pumping units.

A diagram of the possible use of the PS - PSPP mode was shown in Figure. 2. 


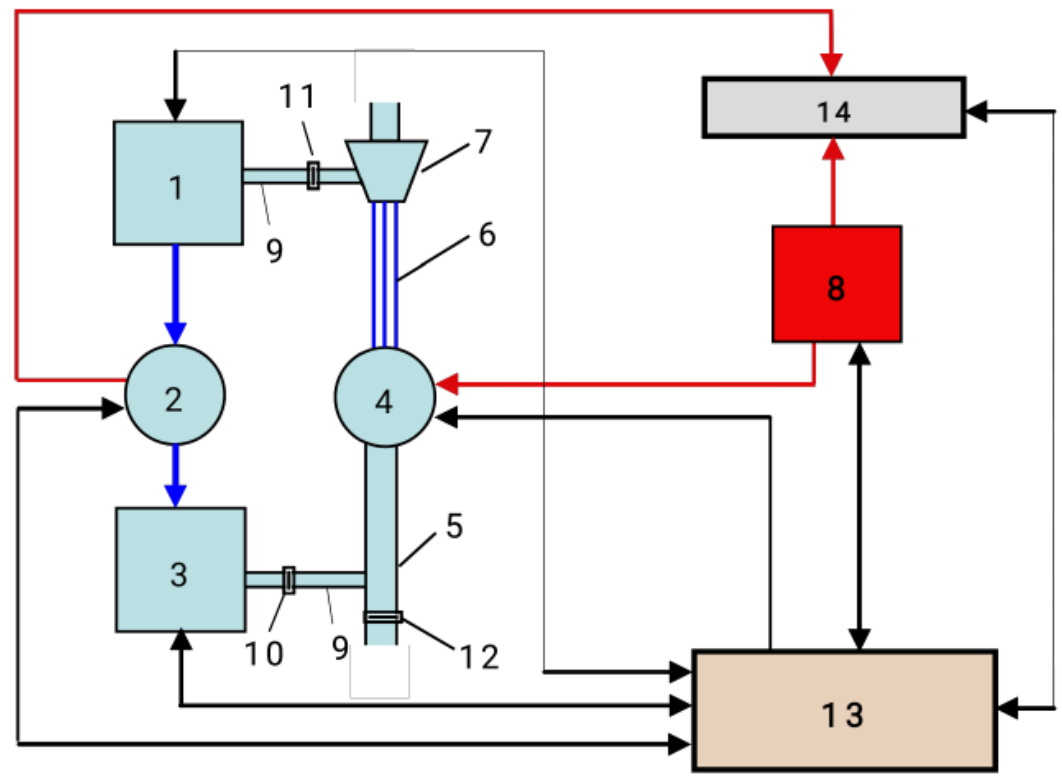

Fig. 2 Scheme of the PSPP for a large pumping station: 1 is upper water body; 2 is HPP; 3 is lower water body; 4 is pump station; 5 is supply channel; 6 are pressure pipes; 7 is pressure basin; 8 is TPP; 9 are connecting channels; 10,11,12 are gates; 13 is control unit; 14 are consumers

The above diagram shows that to carry out the hydro accumulation of energy, it is necessary to create a hydroelectric power station with two reservoirs of the same volume at a pumping station. According to the water supply schedule, in normal modes of the NS with closed gates 10.11 and open gate 12, water is supplied to consumers. In the case of energy storage, the gate 12 closes, and the gates 10, 11 open, and the PS taking water from the lower reservoir 3, pumps it into the upper reservoir 1 through the pressure pipelines 6 and the pressure reservoir 7. During the hours of power generation, water from the upper reservoir 1 is supplied to hydro turbines 2 and through them into the lower reservoir 3 . Thus, whenever energy is accumulated, water will circulate between the reservoirs. It can be seen from this that water is taken from existing sources once to fill water bodies and that energy storage does not require excess water resources, except a small volume to replenish the loss of water.

a) it will be possible to use the excess capacity of pumping stations during the period of night load sags to accumulate water in the upper basin while consuming cheaper and free night energy;

b) the volume of water accumulated in the upper basin can be used during periods of maximum load to generate more expensive and demanded peak energy;

c) in connection with the use of equipment, structures, and a ready-made pressure front of the PS, the costs of the process of hydraulic energy storage are significantly reduced.

Such a mode of operation of the complex is beneficial not only for thermal power plants, in which the technological process is stabilized by reducing switching modes but also for pumping stations, due to compensation of part of the consumed energy due to the station hydroelectric power station and an increase in the utilization factor of the installed capacity.

PS can operate in weekly regulation, even in annual regulation of load capacity, but this requires high costs associated with an increase in additional volumes of reservoirs and PSPP structures. It is advisable to include pumping stations in the hydraulic energy storage system to cover the daily load schedule. 
The choice of parameters and optimization of the PSPP operation mode at large PS in the daily power regulation is carried out with the obligatory fulfillment of the following conditions.

1. According to the balance of produced $E(t)$ and consumed $P(t)$ energy during the period of operation of the PSPP in turbine mode from $t_{1}$ to $t_{k}$

$$
E(t)=\int_{t_{1}}^{t_{k}} P(t) d t
$$

2. By the volume of reservoirs

$$
V_{i} \leq V_{\max }
$$

where $V_{\max }$ is the maximum calculated volume of the upper reservoir, $i$ is the number of the considered options for the participation of the PSPP in covering the daily load.

From these, the second condition follows from the limited possibilities of water resources and the area for water bodies, which require, first of all, to observe the interests of water and agriculture.

If the above conditions are met, the minimum fuel consumption at the TPP can be taken as the objective function, which is solved when the following condition is met

$$
B_{i}=\ni_{T i}(t) \cdot b_{i}+b_{\Pi i} \cdot n_{i} \rightarrow \min ,
$$

where $B_{i}$ is the fuel consumption in TPPs in the $i$ is variant of PSPP; $\mathrm{b}_{i}$ is specific fuel consumption at stationary modes of TPP operation; $b_{\Pi i}$ is the specific fuel consumption when switching TPP units; $n_{i}$ is the number of mode switchings in TPP.

A decrease in the number of mode switchings at TPPs is, first of all, necessary to reduce the amount of fuel consumed, for example, according to the Talimarjan TPP, in 2017, 21 starts and stops of power units were carried out, which consumed 2,459 thousand $\mathrm{m}^{3}$ of natural gas. According to some data, the operation of TPP power units in an alternating mode leads to an overconsumption of fuel by $0.18 \ldots 0.20 \mathrm{~kg} /(\mathrm{kWh})$ and an increase in electricity consumption for own needs [6].

An analysis of the materials of operation of several TPPs shows that each start-stop of a thermal unit entails repairs and revisions to a certain extent to eliminate various problems. The use of a TPP in an alternating mode of operation reduces the overall service life of the equipment by about $20 \%$ [5].

Based on this, the operating mode of a PSPP, which will operate in an integrated system with a TPP, must be coordinated with the fulfillment of condition (3). At the same time, it is proposed to select the PSP parameters in turbine mode in the sequence that is presented in the block diagram shown in Figure. 3. 


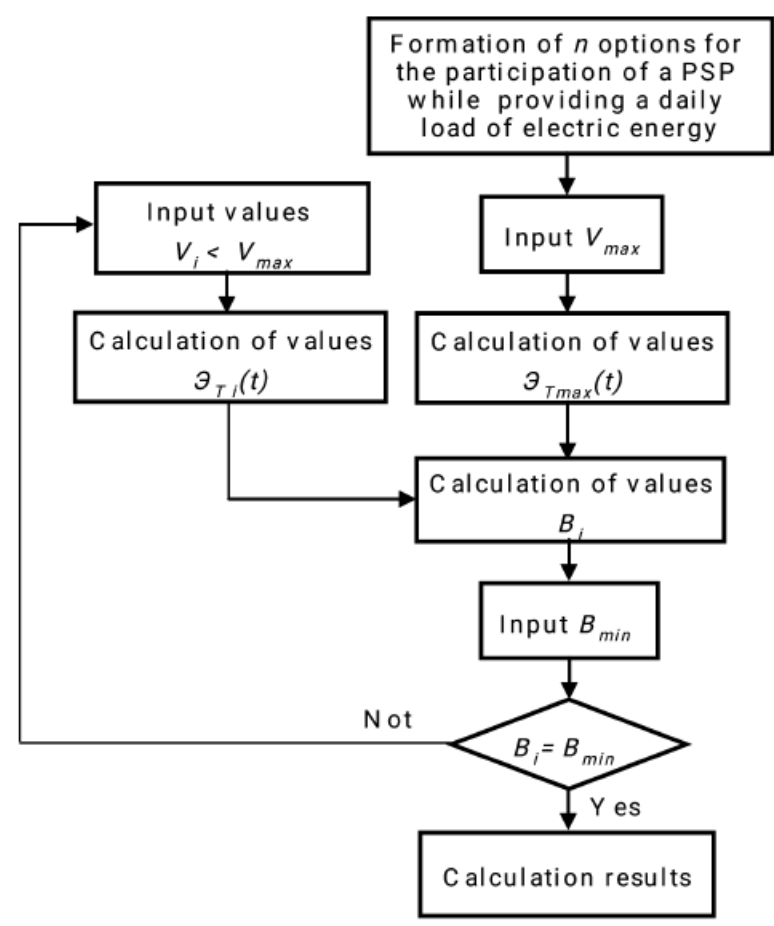

Fig. 3. Block diagram for determining the main parameters of a pumped storage power plant

The formation of $\mathrm{n}$ options for the participation of PSPP in covering the daily load provides for the consideration of various values of the capacities of TPP $N_{T P P j}$ and PSPP in turbine mode $N_{T j}$ in selected time intervals.

$E_{\text {Tmax }}$ values are calculated according to the following formula

$$
E_{\text {Tmax }}=\frac{H_{T a v} \cdot \eta^{t u r}}{367} V_{\max }
$$

From this, we can obtain the fuel consumption in TPP by $B=E_{\text {Tmax }} \cdot b_{i}+b_{n i} \cdot n_{i}$ If $\mathrm{B} \neq \mathrm{B}_{\max }$ then, various options are considered with the values of $E_{t i}$ and $B_{i}$ until a result that satisfies the condition (3) is obtained. To calculate the operating parameters and technical and economic indicators of the PSPP, we have developed software for computers that allow us to calculate the parameters of PSPP in different conditions of their operation with large volumes of materials and information under consideration [21].

\section{Results and Discussion}

Considering the above factors, as one of the options, we propose a layout of the pumped storage power plant at the pumping stations Jizzakh-1, Jizzakh-2, Jizzakh-3, Arnasoy-1, and Arnasoy-2 to integrate them into the process of electricity generation at Syrdarya TPP. The above-named PS is the closest to this TPP.

The total installed capacity of the above pumping stations is 190 MW. Pumping stations supply $350 \mathrm{~m}^{3} / \mathrm{s}$ water to the irrigated land of farms located on an area of 400 thousand hectares.

Because the PSPP operates in the daily regulation mode, the volumes of reservoirs will be relatively small (Figure. 4). 


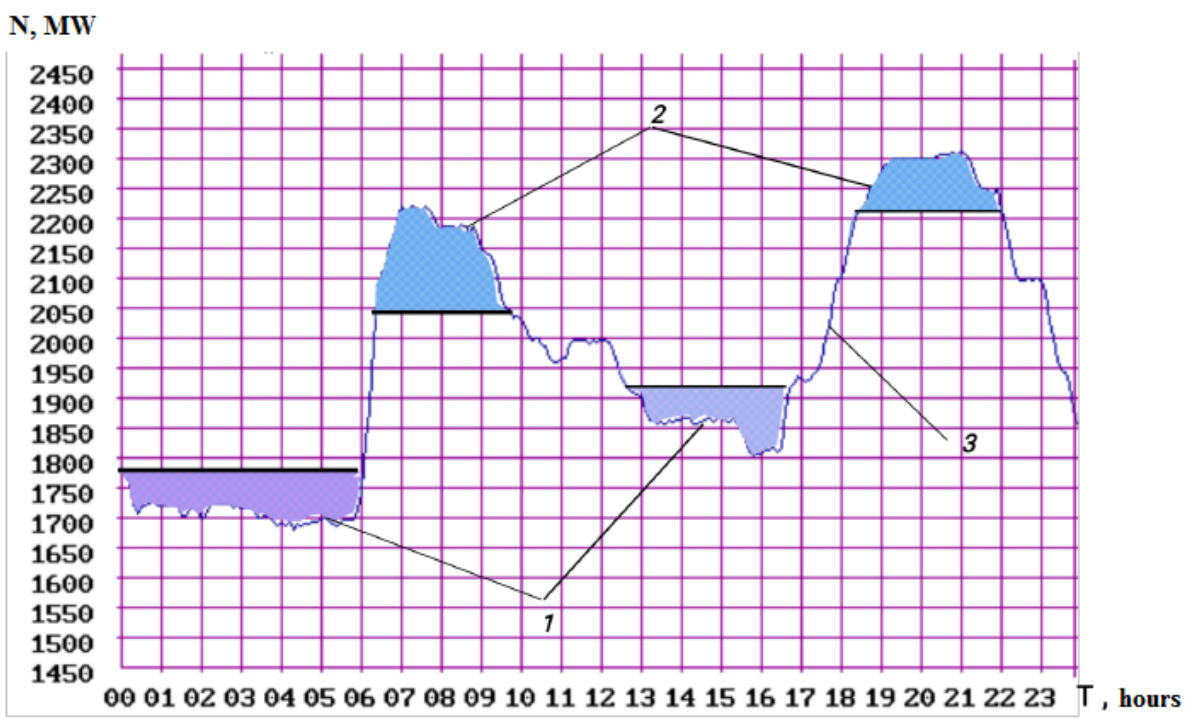

Fig. 4. Schedule of the daily energy production of the Syrdarya TPP from 07.03.2018 at using the PS - PSPP mode: 1 is energy consumption mode (pumping mode); 2 is power generation mode (turbine mode); 3 is day load schedule.

During periods of minimum electricity generation (from $01^{00}$ to $06^{00}$ hours and from $13^{00}$ to $16^{30}$ ), the PS is switched to forced operation with high water consumption, for which the Syrdarya TPP is additionally supplied with electricity within $690 \ldots 700 \mathrm{MW} \cdot$ hour using less than $40 \%$ of the established power of the PS, i.e., on average 75 MW (Figure. 4). Pumping stations, using this energy, pump the corresponding volume of water from the lower reservoirs into specially built in upper reservoirs, i.e., energy is being stored. When the time of maximum loads comes (from $06^{30}$ to $9^{30}$ and from $18^{30}$ to $22^{00}$ ), water from the upper reservoirs is supplied to the turbines of the hydroelectric power station, and the generation of electricity is ensured in the corresponding volume by leveling the production schedule in its peak part, and the waste water is directed to the lower reservoir.

Obviously, at the same time, the operating mode of the Syrdarya TPP is improving due to the prevention of abrupt changes (switching) in the schedule of electricity generation (the coefficient of the unevenness of the schedule changes from 0.74 to 0.80 ).

The average capacity of the PSPP in pumping mode, taking into account losses in the lines and the transformer for both modes, we take $\sum N_{P S P P}^{H}=75 / 0.94=80 \mathrm{MW}$.

A pumped storage plant in pumping mode has approximately the following parameters:

1. Power $N_{P S P P}^{H}=80 M W$;

2. Average weighted head $H=45.0 \mathrm{~m}$;

3. Time of filling the upper reservoir with two-time intervals $-5+3.5=8.5$ hours;

4. Efficiency in pumping mode - $\eta_{\text {pump }}=0.8$.

In this mode of operation, the total volume of reservoirs should have the following value

$$
V=\frac{N_{P S P P}^{H} \cdot 367 \cdot t_{H} \cdot \eta_{\text {tur }}}{\mathrm{H}}=\frac{80 \cdot 367 \cdot 8,5 \cdot 0,8}{45}=4436622 \mathrm{~m}^{3}
$$

The main parameters of the PSPP in turbine mode are determined in the following order.

1. Total generated energy of PSPP in turbine mode

$E=V \cdot H \cdot \eta_{\text {tur }} / 367=4436622 \cdot 45 \cdot 0.8 / 367=435200 \mathrm{~kW} \cdot$ hour

where $\eta_{\text {tur }}$ - is the efficiency of the turbine mode, $\eta_{\text {tur }}=0.80$. 
2. Operating time of the PSPP in turbine mode according to the daily schedule for 1 interval 3 hours, for interval 2 - 3.5 hours.

3. Average capacity of the PSPP in turbine mode $N_{P S P P}^{T}=E /\left(t_{1}+t_{2}\right)=435200 / 6.5=$ $66.95 \mathrm{MW}$.

4. 4.Total water consumption of PSPP in turbine mode $\sum Q_{t u r}=N_{P S P P}^{T} / 9.81 \cdot H \cdot \eta_{t}=66950 / 9.81 \cdot 45 \cdot 0.80=189.6 \mathrm{~m}^{3} / \mathrm{s}$

\section{Conclusions}

The results of technical and economic calculations showed the feasibility of using pumped storage power plants based on large PS for water management. For example, with the introduction of hydraulic energy storage in 5 pumping stations when coordinating their operating mode with the energy production mode of the Syrdarya TPP, only because of the difference in the cost of energy in the HPP and gas installations of the TPP, you can get a profit of $3.0 \ldots 4.0$ million dollars in a year. In these calculations, data from the Fraunhofer Institute for Solar Energy Systems were taken into account on the cost of energy for gas installations, equal to $11.03 \ldots 21.94$ Eurocents / $\mathrm{kWh}$, and the cost of energy in hydroelectric power plants, equal to 0.047 dollars / $\mathrm{kWh}$ [22]. When environmental costs, system services, and other capabilities are taken into account, the gain is undoubtedly even greater.

\section{References}

1. C. J. Yang, Pumped hydroelectric storage: Technical report. (2011).

2. Paul Denholm, Erik Ela, Brendan Kirby and Michael Milligan The Role of Energy Storage with Renewable Electricity Generation.Technical Report NREL/TP -6A247187. (2010).

3. Elistratov V V The use of renewable energy. St.Petersburg, Publishing house Polytechnic University, p .225. (2008).

4. Zubarev V V Storage power plants and their use inpower systems. "Informenergo", issue 4, Moscow, pp.34-38. (1986)

5. Sinyugin V Yu Hydro-storage power plants in modern electric power industry, ENAS, Moscow, p. 352. (2008).

6. Sheinman L B Pumped storage power plants. Energiya, Moscow, p. 184. (1978).

7. Energy storage — packing some power. The Economist. (2011). Retrieved 2012-03-11; 2012. http://www.economist.com/node/21548495? frsc $=\mathrm{dg} \% 7 \mathrm{Ca}$

8. Muhammadiev M M, Urishev B U 2019 Problems of using pumped storage power Plants to improve the reliability and controllability of electric power system of the Republic of Uzbekistan. E3S Web Conf. Rudenko Intern. Confer.e "Method. problems in reliability study of large energy systems" (RSES 2019), no5, Volume 139,. doi.org/10.1051/e3sconf/201913901009/

9. Brandi A.Antal Pumped Storage Hydropower: A Technical Review.B.S., University of Colorado, p. 84. (2014).

10. Istvan Taczi Pumped Storage Hydroelectric Power Plants: Issuesand Applications, Energy Regulators Regional Association. Budapest, Hungary,p.11. (2016).

11. Muhammadiev M M, Urishev B U Pumped storage power plants."Fan va technologiya", Tashkent, p. 212. (2018).

12. Ministry of Energy of the Republic of Uzbekistan.mienergy.uz [13]. Energy Storage Technology and Cost Characterization Report, (2019). 
13. www.energy.gov/sites/prod/files/2019/07/f65/Storage $\% 20$ Cost $\% 20$ and $\% 20$ Performan ce\%20Characterization\%20Report_Final.pdf

14. Urishev B Decentralized Energy Systems, Basedon Renewable Energy Sources. USA, Journal Applied Solar Energy, vol.55, no. 3,pp. 207-212. (2019).

15. Energy Storage Monitor Latest trends in energy storage 2019. www.worldenergy.org/assets/downloads/ESM_Final_Report_05-Nov-(2019).pdf

16. C.Yang and R.B.Jackson «Opportunities and barriers to pumped-hydro energy storage in the United States,» Renew. Sustain. Energy Rev., vol. 15, no.1, pp.839-844. (2011).

17. Deane J, Y Gallachyir B, McKeogh E Techno-economic review of existing and new pumped hydro energy storage plant. Renewable Sustainable Energy Rev, no 14,pp.1293-1302. (2010).

18. Connolly D, LundH, Finn P, Mathiesen B V, Leahy M Practical operation strategies for pumped hydroelectric energy storage (PHES) utilizing electricity pricearbitrage. Energy Policyno 39, pp.4189-96. (2011)

19. Ministry of water management of the Republic of Uzbekistan.www.water.gov.uz

20. Urishev B. Selection of Parameters of Pumped Storage Power Plants at Large Pumping Stations for Water Use.Journal Applied Solar Energy, Vol.54,No. 6, pp.477480. (2019).

21. Mukhammadiev M M, Urishev B U, Dzhuraev K S, Gadaev S K, Sobirov A T Program for determining the operating parameters of PSPP, no.DGU05155. Agency for Intellectual Property of the Republic of Uzbekistan, Bul.no.3. (2018).

22. Mukhammadiev M.M, Urishev B. U., Abduaziz uulu A, Gadaev S. K, Zhankabylov S.U. Issues of using local energy systems with hydraulic energy storage in the power system of the Republic of Uzbekistan. ICECAE, Tashkent. (2020).

23. Christoph Kost, Shivenes Shammugam,Verena Julch, Huyen-tran Nguyen, Thomas Schlegl (2018) Levelized cost of electricity renewable energy technologies. Fraunhofer institute for solar energy systems. Available: https://www.ise.fraunhofer.de/content/ dam/ise/en/documents/publications/studies/EN(2018)_FraunhoferISE_LCOE_Renewable_Energy_Technologies.pdf

24. Mukhammadiev M.M., Dzhuraev K.S Justification of the energy and economic parameters of pumped storage power plants in Uzbekistan. International journal “Applied Solar Energy”, Vol. 56, №3, pp.227-232. (2020).

25. M Mukhammadiev, O Glovatskiy, N Nasyrova, N Karimova, A Abduaziz uulu and A Boliev. Assessment of investment technologies for use of hydro - accumulating stations on intermediate channels of irrigation systems and water reservoirs. IOP Conf. Series: Earth and Environmental Science 614 (2020) 012088 doi:10.1088/1755$1315 / 614 / 1 / 012088$ 